\section{Benzaldehyde as a Soil Fumigant, and an Apparatus for Rapid Fumigant Evaluation}

\author{
Charles L. Wilson, Jose M. Solar, and Ahmed El Ghaouth \\ U.S. Department of Agriculture, Agricultural Research Service, Appalachian \\ Fruit Research Station, 45 Wiltshire Road, Kearneysville, WV 25430
}

Deborah R. Fravel

U.S. Department of Agriculture, Agricultural Research Service, Biocontrol of Plant Disease Laboratory, Room 275, Building 011A, Beltsville Agricultural Research Center, Beltsville, MD 20705-2350

\section{Additional index words. soil fumigation, methyl bromide, natural fungicides, natural fumigants}

\begin{abstract}
An apparatus was developed for the rapid and facile evaluation of soil fumigants in a controlled manner using small volumes of soil. The apparatus consisted of a manifold to which were attached six canisters containing a loamy sand soil (adjusted to-100 kPa soil water potential). The soil was infested with either conidia of Fusarium oxysporum or Trichoderma harzianum; sclerotia of Sclerotinia minor; ascospores of Talaromyces flavus; vermiculite colonized with Pythium aphanidermatum; or beet (Beta vulgaris L., cv. Detroit Red) seed colonized with Rhizoctonia solani. Using nitrogen gas $\left(\mathbf{N}_{2}\right)$ as a carrier gas, either $\mathrm{N}_{2}$ or $\mathrm{N}_{2}$ plus benzaldehyde was passed continuously through the soil for 24,48 , or 72 hours. At all three exposure times, benzaldehyde $+\mathrm{N}_{2}$ reduced viability of $R$. solani and $S$. minor, and reduced populations of $P$. aphanidermatum and $T$. harzianum. Populations of $F$. oxysporum were reduced after 48 and 72 hours of exposure to benzaldehyde, whereas populations of $T$. flavus were reduced only after 72 hours of exposure. Fumigation with benzaldehyde $+\mathrm{N}_{2}$ for 24 hours did not affect soil $\mathrm{pH} 1$ week after exposure, but fumigation for 48 or 72 hours temporarily lowered pH from an average of 6.86 to 5.57 and 5.32, respectively. The biocontrol fungus, $T$. flavus, was less sensitive to benzaldehyde than the pathogens or the biocontrol fungus, $T$. harzianum. Thus, combining $T$. flavus with benzaldehyde to enhance biocontrol may be possible.
\end{abstract}

Methyl bromide (MB) has played a major role in preplant soil treatments for certain high-value crops like strawberries and tomatoes. Growers fumigate soil with methyl bromide to rid it of various soilborne root pathogens, harmful nematodes, and weeds before planting. About $80 \%$ of the methyl bromide produced in the United States is used to ready fields before planting [U.S. Environmental Protection Agency (EPA), 1995].

The projected loss of MB as a soil fumigant in 2005 has underscored the need for reliable, environmentally and economically acceptable alternative methods for soil disinfestation (United Nations: Environmental Program, 1992, 1994). Agriculture has also depended heavily on $\mathrm{MB}$ for quarantine treatments for the exportation of fruit and vegetables (EPA, 1995). A variety of alternatives to $M B$ has been proposed, including other chemical fu-

Received for publication 1 July 1998. Accepted for publication 26 Oct. 1998. We gratefully acknowledge the excellent technical assistance of Brian Otto, Mat Brazier, Lynn Kennaly, and Charles Tate and helpful suggestions provided by Dr. William Connick, Jr., USDA-ARS, New Orleans, La. The cost of publishing this paper was defrayed in part by the payment of page charges. Under postal regulations, this paper therefore must be hereby marked advertisement solely to indicate this fact. compound and readily decomposes to benzoic acid and water (Do et al., 1969). Benzaldehyde has been reported to have activity as a fungicide (Wilson et al., 1987) in vitro and as a nematicide in soil (Bauske et al., 1994).

Evaluation of the effectiveness of soil fumigants applied to planting beds or greenhouse containers to control pathogens, insects, and weed seeds is difficult. Present methodologies require that the soil be fumigated in situ. This involves the fumigation of large volumes of soil and elaborate evaluation procedures to determine the effectiveness of the fumigant. In the present investigation, we devised an apparatus to more conveniently and rapidly evaluate the effectiveness of fumigants for the control of soilborne pathogens.

We elected to test natural soil fumigants in a system that allowed the continuous flow of the fumigant through a container rather than placing the soil and fumigant together in a closed system. This was to prevent high $\mathrm{CO}_{2}$ buildup that occurs in a closed system. Carbon dioxide is fungicidal to soilborne pathogens (data not shown) and its activity confounds the effects of potential fumigants when they are tested. Also, continuous flow of the fumigant through the soil provided a uniform concentration and distribution of the test fumigant.

This research was undertaken to 1) develop a system for the rapid and reliable evaluation of soil fumigants, and 2) evaluate the capacity of a naturally occurring product to kill plant pathogenic and biocontrol fungi in soil.

\section{Materials and Methods}

Fumigation apparatus. The soil fumigation apparatus (Figs. 1-3) consisted of a manifold (Figs. 1D, 2C) to which multiple gastight, cylinder-shaped canisters (Figs. 1H, 2A), each with a small opening in the end, were attached with a quick-coupler (Fig. 2B). Small pieces of rock wool were placed at the openings at each end of the soil-containing canisters to prevent clogging by soil particles. Pressurized



Fig. 1. Schematic of soil fumigation apparatus: (A) nitrogen tank and regulators; (B) stainless steel gastight container; (C) plastic container filled with charcoal loaded with fumigant; (D) stainless steel manifold to which gas flow regulator and soil-containing canisters are attached; $(\mathbf{E})$ gas flow regulator; $(\mathbf{F})$ quick coupler attachment for easy removal of soil-containing canisters; $(\mathbf{G})$ soil-containing canisters; $(\mathbf{H})$ pathogen- and antagonist-infested soil; and (I) outlet nipple to which flow meter is attached. 


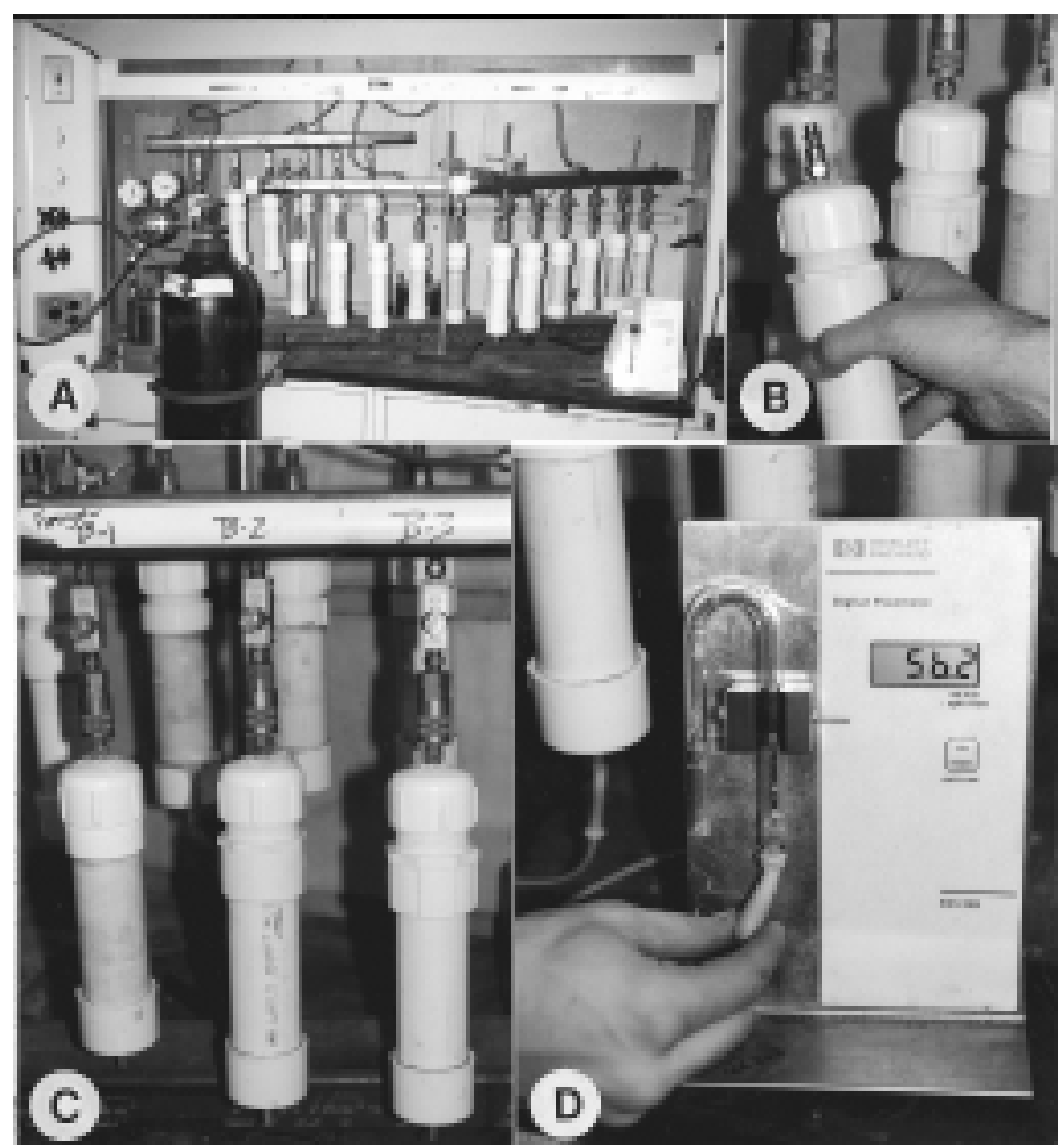

Fig. 2. Soil fumigation apparatus: (A) three manifolds in a hood with six soil-containing canisters attached to a fumigant container and nitrogen tank; (B) soil canister detached from the quick coupler attached to the manifold; (C) three soil canisters with flow regulators between the manifold and the quick couplers; and (D) digital flowmeter attached to the nipple at the end of the soil-containing canister.
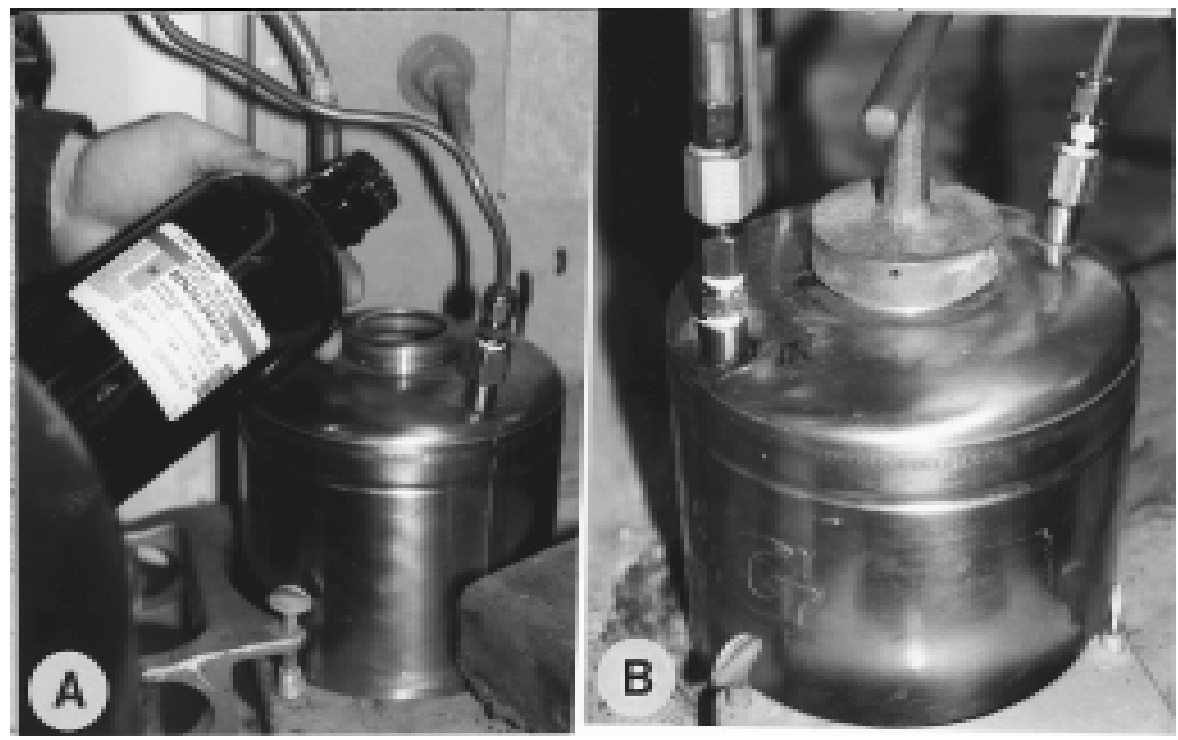

Fig 3. Stainless steel can in which fumigants are placed: (A) benzaldehyde being added to the charcoal in the inner container; and (B) can showing the inlet from the nitrogen tank and outlet to the manifold. gas flowed from the manifold through each canister and the flow-rate was regulated with an adjustable gas-flow valve (Fig. 2C) between the manifold and the soil canister. A stainless steel gas pressure tank (Fig. $3 \mathrm{~A}$ and B) was attached to a container that held the volatiles to be tested as soil fumigants. The container was also attached to the manifold through a gastight hose (Fig. 1). Gas pressure was released from the pressure tank, which pressurized the container with the volatiles to be tested. The volatile was then propelled through the manifold with $\mathrm{N}_{2}$ gas, where it was distributed throughout the canisters containing the soil (Fig. 1H). To avoid microbial toxicity that occurs under anaerobic conditions and high $\mathrm{CO}_{2}$ buildup, the fumigant flowed continuously through the canister rather than being retained in an airtight compartment. This system allowed uniform retention of the candidate fumigant in the soil within the canister for a defined period and the treatment of multiple replicates at the same time. Uniform fumigation of each canister was obtained by maintaining the same flow rate through each canister. Once soil samples were fumigated, the canisters were opened and soils destructively assayed for fungal activity after 24, 48, and $72 \mathrm{~h}$.

Fumigant application. The fumigant benzaldehyde was impregnated onto a carbon support (Fig. 1C) by means of the incipient wetness method (i.e., the liquid fumigant was added to the carbon up to the point of saturation). One hundred milliliters of liquid benzaldehyde was added to $280 \mathrm{~g}$ of activated charcoal. The benzaldehyde-impregnated carbon was deposited in a 1-L aluminum container. This container (Fig. 1B) was equipped with a gas inlet, which reached almost to the bottom, and a gas outlet orifice on the top. Nitrogen gas $\left(\mathrm{N}_{2}\right)$ from a pressurized tank was connected to the fumigant container and manifold holding the soil-containing canisters. As $\mathrm{N}_{2}$ flowed thorough the aluminum container, the fumigant, which was desorbed from the carbon support, was transported through the canisters containing soil (Fig. 1G). Each canister contained $100 \mathrm{~g}$ of soil and was subjected to a volumetric flow rate of $50 \mathrm{~mL} \cdot \mathrm{min}^{-1}$ at ambient temperature (Fig. 2D).

For control treatments, soil was exposed to $\mathrm{N}_{2}$ alone. Preliminary experiments indicated that exposure of the fungi to $\mathrm{N}_{2}$ alone was equivalent to exposure to air.

To determine the amount of fumigant applied to the soil during the fumigation process, the weight of the fumigant container plus fumigant was recorded initially and again after 1-d intervals. This was then converted to milligrams of volatile per grams of soil, yielding values of $0.263,0.109$, and 0.470 for 24 , 48 , and $72 \mathrm{~h}$, respectively.

Soil infestation. Four pathogens were selected to represent unrelated taxonomic groups. They were Fusarium oxysporum, Pythiumaphanidermatum, Rhizoctonia solani, and Sclerotinia minor. In addition, the effect of benzaldehyde was evaluated on two biocontrol fungi, Trichoderma harzianum and Talaromyces flavus. 
Soil used in all experiments was Galestown gravelly loamy sand ( $\mathrm{pH} 5.8$, and $77.8 \%$ sand, $12.6 \%$ silt, $9.6 \%$ clay, $0.6 \%$ organic matter, cation exchange capacity 4.0) collected in Beltsville, Md. Soil was infested with fungi the day it was collected, passed through a 0.5 cm-pore-size screen, and sent by overnight mail to Kearneysville, W.Va., for fumigation.

All fungi used were from the collection of the Biocontrol of Plant Diseases Laboratory, U.S. Dept. of Agriculture, Agricultural Research Service, Beltsville, Md. F. oxysporum FGOR3 (Larkin et al., 1996) is an orangecolored mutant derived from $F$. oxysporum and is pathogenic on watermelon (Larkin et al., 1993). It is comparable to the wild-type $F$. oxysporum in growth, sporulation, and pathogenicity.

Inoculum of $R$. solani isolate Rs23A was prepared on sterile beet seed as previously described by Papavizas and Lewis (1986). To produce inoculum of Pythium aphanidermatum, $4 \mathrm{~L}$ of vermiculite (grade 3 ; Schundler, Metuchen, N.J.) were mixed with 1.3 L V-8 vegetable juice (Campbell Soup Co., Camden, N.J.), $6.5 \mathrm{~g} \mathrm{CaCO}_{3}$, and $70 \mathrm{~g}$ potato dextrose broth (Difco, Detroit). This mixture and flasks were autoclaved for $1 \mathrm{~h}$ each day on two consecutive days. Flasks were inoculated with three $0.7 \mathrm{~cm}$-diameter disks of $P$. aphanidermatum from a 3-week-old water agar culture and incubated under constant fluorescent light under ambient conditions. Eighteen $250-\mathrm{g}$ portions of soil (water content of $4.6 \%$ ) were mixed with $10 \mathrm{~g}$ each of the infested vermiculite mixture. The vermiculite mixture contained $\approx 1.7 \times 10^{3}$ propagules $/ g$.

Talaromyces flavus isolate Tf- 1 was maintained on potato dextrose agar (PDA) (Difco). After 4 to 8 weeks of incubation in the dark at $27{ }^{\circ} \mathrm{C}$, cleistothecia were scraped from the agar and suspended in sterile distilled water (SDW), then disrupted in a blender for $2 \mathrm{~min}$. The resulting suspension was adjusted to $10^{6}$ ascospores/mL. Each of eighteen 250 -g portions of soil were mixed thoroughly with 10 $\mathrm{mL}$ of this suspension.

Fusarium oxysporum FGOR3 was maintained on PDA in the dark at $25^{\circ} \mathrm{C}$. After 3 weeks of incubation at $25^{\circ} \mathrm{C}$, conidia were collected and blended using the same procedure as for ascospores of $T$. flavus to achieve a suspension of $10^{6}$ conidia/mL. Eighteen 250 g portions of soil were each mixed thoroughly with $10 \mathrm{~mL}$ of this suspension.

Sclerotia of $S$. minor isolate $5 \mathrm{~s}-135 \mathrm{~L}$ were produced on PDA at $25{ }^{\circ} \mathrm{C}$. After 3 weeks, sclerotia were collected by wet sieving through a screen (0.18-mm pore size). Eighteen $250-\mathrm{g}$ portions of soil were each infested with $6.25 \mathrm{~g}$ of sclerotia.

Biomass of $T$. harzianum isolate Th- 87 was produced as previously described (Papavizas et al., 1984) and stored at $5{ }^{\circ} \mathrm{C}$ for up to 6 months before use. Prior to use, $T$. harzianum was plated onto a medium (TME) that is semiselective for Trichoderma spp. (Papavizas and Lumsden, 1982) to determine viable colony forming units (CFU). Eighteen 255 -g portions of soil were infested with biomass, resulting in $10^{6} \mathrm{CFU} / \mathrm{g}$ soil $(\approx 10 \mathrm{~g})$.
Enumeration of fungal populations. Populations of $F$. oxysporum were determined by dilution plating onto Komada's agar medium (KA) (Komada, 1975). Similarly, populations of $T$. flavus and $T$. harzianum were determined on media that were semiselective for $T$. flavus (TFA) (Marois et al., 1984), or TME, respectively. Additional soil from each replicate was weighed, dried overnight at $100{ }^{\circ} \mathrm{C}$, then reweighed to express colony counts as $\mathrm{CFU} / \mathrm{g}$ dry weight of soil. Soil infested with $F$. oxysporum or $T$. harzianum was incubated under constant fluorescent light at $25^{\circ} \mathrm{C}$, whereas plates from soil infested with $T$. flavus were incubated in the dark at $27^{\circ} \mathrm{C}$. Colonies of $F$. oxysporum ,T. flavus, and $T$. harzianum were counted after 6,10 , and $7 \mathrm{~d}$, respectively.

Beet seed infested with $R$. solani were recovered by wet sieving (2-mm pore size), washed 10 min under running tap water, and plated onto water agar (WA). Plates were examined after $24 \mathrm{~h}$ incubation in the dark under ambient conditions, and the number of beet seed from which $R$. solani had grown was recorded.

Soil containing $P$. aphanidermatum was serially diluted and plated onto corn meal agar plus antibiotics (CA) (Harris and Sim- mers, 1968). The number of CFU was recorded after $24 \mathrm{~h}$ of incubation under ambient conditions.

Sclerotia of $S$. minor were recovered by wet sieving through nylon mesh $(0.18-\mathrm{mm}$ pore size) as previously described (Adams, 1979). Sclerotia were plated onto WA amended with $0.0332 \mathrm{mg} / \mathrm{L}$ rose bengal (Fisher, Pittsburgh). After 5 and $10 \mathrm{~d}$ incubation in the dark at $25^{\circ} \mathrm{C}$, plates were examined, and hyphal growth was recorded.

Soil $\mathrm{pH}$. For some experiments, after soil was recovered from the canisters and subsamples removed for enumeration of fungi, the remaining soil was again adjusted to -100 $\mathrm{kPa}$ and soil $\mathrm{pH}$ was determined weekly for each replicate. Ten grams of soil was placed in $25 \mathrm{~mL}$ distilled water and mixed for $30 \mathrm{~s}$. The soil suspension was kept under ambient conditions for $1 \mathrm{~h}$, then mixed for $30 \mathrm{~s}$, and the $\mathrm{pH}$ was recorded weekly for 4 weeks.

Experimental design and statistical analysis. Eighteen soil-containing canisters were fumigated during each experiment. Soil samples from each canister of the fumigator were considered one replicate. Means of population counts of soil pathogens and antagonists were compared using the analysis of variance procedure in the Statistical Analysis System


Fig. 4. Effect of benzaldehyde + nitrogen gas on: (A) the ability of $R$. solani to grow from colonized beet seed; and (B) sclerotial germination of S. minor. Vertical bars represent standard errors of the means. 




Fig. 5. Effects of benzaldehyde + nitrogen gas on populations of the pathogens (A) F. oxysporum, and (B) P. aphanidermatum and on the biocontrol fungi (C) T. flavus and (D) T. harzianum in soil. Control treatments received the carrier gas (nitrogen) only. Vertical bars represent standard errors of the means.

(SAS, Cary, N.C.). All experiments were repeated twice. Since there were no significant differences between the two runs of each experiment, runs were combined and the data presented are for the average of the two runs of each experiment.

\section{Results}

Benzaldehyde $+\mathrm{N}_{2}$ significantly reduced the viability of $R$. solani and $S$. minor at all three exposure times (Fig. 4). After only 24, 48 , or $72 \mathrm{~h}$ exposure to benzaldehyde $+\mathrm{N}_{2}, R$. solani grew from $29 \%, 35 \%$, and $7.5 \%$ of beet seed, respectively, compared to growth from 99\% of the beet seed in the control treatment. All sclerotia of $S$. minor exposed to benzaldehyde $+\mathrm{N}_{2}$ for $72 \mathrm{~h}$ failed to germinate whereas $95 \%$ of the sclerotia in the control treatment germinated. The 24- and 48-h exposure duration to benzaldehyde $+\mathrm{N}_{2}$ resulted in some sclerotia germination, but the percentages were

after $24 \mathrm{~h}$ exposure, and $T$. harzianum was killed after $48 \mathrm{~h}$ exposure to benzaldehyde.

Although fumigation with benzaldehyde + $\mathrm{N}_{2}$ for $24 \mathrm{~h}$ did not affect soil $\mathrm{pH} 1$ week after exposure, fumigation for 48 or $72 \mathrm{~h}$ significantly $(P \leq 0.05)$ lowered soil $\mathrm{pH}$ from an average of 6.86 to 5.57 and 5.32, respectively (Data not shown). Two weeks after fumigation there were no differences among treatments with respect to soil $\mathrm{pH}$.

\section{Discussion}

Any "out of bed" screening procedure for soil fumigants cannot fully emulate conditions in the field. When fumigants are tested in completely enclosed gastight containers, the buildup of $\mathrm{CO}_{2}$ and decrease in $\mathrm{O}_{2}$, through microbial respiration, produces conditions that are antimicrobial, which confounds the results from the fumigants being tested. Nitrogen gas was selected as a carrier for the fumigants because of its nonreactivity with the fumigant and the soil. When we fumigated with $\mathrm{N}_{2}$ alone, the effect on soil pathogens was the same as fumigation with air.

Benzaldehyde $+\mathrm{N}_{2}$ was an effective fumigant against the major soil pathogens $F$. oxysporum, $R$. solani, $P$. aphanidermatum, and $S$. minor. Benzaldehyde is a desirable alternative to $\mathrm{MB}$ since it is inexpensive, biodegrades easily, and its eventual breakdown products $\left(\mathrm{CO}_{2}\right.$ and $\left.\mathrm{H}_{2} \mathrm{O}\right)$ are harmless to humans and the environment.

The differential effect of benzaldehyde + $\mathrm{N}_{2}$ on soil pathogens and antagonists may be fortuitous and could provide a way of promoting biological control through fumigation. By selecting natural fumigants that inhibit pathogens and promote antagonists, a favorable environment could be created in the soil for antagonist development and subsequent disease suppression. Canullo et al. (1992) found that repeated treatments of soil with furfuraldehyde significantly increased populations of Trichoderma sp. and bacteria.

Although fumigation with benzaldehyde + $\mathrm{N}_{2}$ significantly lowered soil $\mathrm{pH}$ values initially, within 2 weeks the $\mathrm{pH}$ returned to the control level. Thus, the changes in soil $\mathrm{pH}$ are temporary and should not interfere with agricultural production requirements.

Some fungitoxic plant volatiles may provide alternatives to $\mathrm{MB}$ for the fumigation of fruit, as several have been shown to have fungicidal activity (Wilson et al., 1987, 1997). Exploration has only begun of the rich reservoir of natural fungicides produced by plants as alternatives to MB. Combinations of such compounds could yield synergistic fungicidal effects. The screening apparatus that we have described should accelerate exploration of natural volatiles as soil fumigants.

The banning of methyl bromide as a preplant treatment for horticultural crops in the year 2005 will cause major problems in the culture of strawberries, tomatoes, and other vegetables. Among the efforts to find effective alternatives to methyl bromide for soil fumigation, the use of natural plant-derived volatiles is promising.

\section{Literature Cited}


aromatic compounds. Nematropica 24:143-150.

Canullo, G.H., R. Rodriquez-Kabana, and J.W. Kloepper. 1992. Changes in soil microflora associated with control of Sclerotium rolfsii by furfuraldehyde. Biocontrol Sci. Technol. 2:159169.

Do, J.Y., D.K. Salunkhe, and L.E. Olson. 1969. Isolation, identification and comparison of the volatiles of peach fruit as related to harvest maturity and artificial ripening. J. Food Sci. 34:618-621.

Harris, R.F. and L.E. Simmers. 1968. Plate dilution frequency technique for assay of microbial ecology. Appl. Microbiol. 16:330-334.

Katan, J. and J. DeVay. 1991. Soil solarization. CRC Press, Boca Raton, Fla.

Komada, H. 1975. Development of a selective medium for quantitative isolation of Fusarium oxysporum from natural soils. Rev. Plant Prot. Res. 8:114-125.

Larkin, R.P., D.L. Hopkins, and F.N. Martin. 1993. Ecology of Fusarium oxysporumf. sp. niveum in soils suppressive and conducive to Fusarium wilt of watermelon. Phytopathology 83:11051116.

Larkin, R.P., D.L. Hopkins, and F.N. Martin. 1996. Suppression of Fusarium wilt of watermelon by nonpathogenic Fusarium oxysporum and other microorganisms recovered from a disease-suppressive soil. Phytopathology 86:812-819.

Litshitz, R., M. Tabachnik, J. Katan, and I. Chet. 1983. The effect of sublethal heating on sclerotia of Sclerotium rolfsii. Can. J. Microbiol. 29:1607-1610.

Luckey, T.D. 1980. Hormesis with ionizing radiation. CRC Press, Boca Raton, Fla.

Marois, J.J., D.R. Fravel, and G.C. Papavizas. 1984. Ability of Talaromyces flavus to colonize the rhizosphere and its interaction with Verticillium dahliae. Soil Biol. Biochem. 16:387-390.

Ohr, H.D., J.J. Sims, N.M. Grench, J.O. Becker, and M.E. McGriffen. 1995. Methyl iodide, an ozone safe alternative for methyl bromide as a soil fumigant. Plant Dis. 80:731-735.

Papavizas, G.C., M.T. Dunn, J.A. Lewis, and J. Beagle-Ristaino. 1984. Liquid fermentation technology for experimental production of biocontrol fungi. Phytopathology 74:1171-1175.

Papavizas, G.C. and J.A. Lewis. 1986. Methods for isolating, identifying, and producing inoculum of Rhizoctonia solani, p. 50-53. In: K.D. Hickey (ed.). Methods for evaluating pesticides for control of plant pathogens. Amer. Phytopathol. Soc., St. Paul, Minn.
Papavizas, G.C. and R.D. Lumsden. 1982. Improved medium for isolation of Trichoderma spp. from soil. Plant Dis. 66:1019-1020.

Solar, J.M., F.J. Derbyshire, and L.R. Radovic. 1991. Effects of surface and structural properties of carbons on the behavior of carbon-supported molybdenum catalysis. J. Catalysis 129:330-334.

United Nations: Environmental Program. 1992. Methyl bromide: Atmospheric science, technology, and economics. Montreal Protocol Assessment Suppl. UNEP. June.

United Nations: Environmental Program. 1994. Montreal protocol on substances that deplete the ozone layer. UNEP. Rpt. on Methyl Bromide Tech. Options Comm. 1955 Assessment. EPA 430

U.S. Environmental Protection Agency. 1995. Methyl bromide consumption estimates. USEPA Stratospheric Protection Div., Washington, D.C.

Wilson, C.L., J.D. Franklin, and B.E. Otto. 1987. Fruit volatiles inhibitory to Monolinia fructicola and Botrytis cinerea. Plant Dis. 71:316-319.

Wilson, C.L., J.M. Solar, A. El Ghaouth, M.E. Wisniewski. 1997. Rapid evaluation of plant extracts and essential oils for antifungal activity against Botrytis cinerea. Plant Dis. 81:204-210. 